\title{
Genetic Mouse Models as In Vivo Tools for Cholangiocarcinoma Research
}

\author{
Oihane Erice ${ }^{1}$, Adrian Vallejo ${ }^{1}$, Mariano Ponz-Sarvise ${ }^{2,3}{ }^{\circledR}$, Michael Saborowski ${ }^{4}{ }^{(}$, \\ Arndt Vogel ${ }^{4}$, Diego F. Calvisi ${ }^{5}$, Anna Saborowski ${ }^{2, *,+}$ and Silvestre Vicent $1,3,6, *,+$ (D) \\ 1 Center for Applied Medical Research, Program in Solid Tumors, University of Navarra, 31008 Pamplona, \\ Spain; oeazparren@unav.es (O.E.); avallejo.3@alumni.unav.es (A.V.) \\ 2 Department of Medical Oncology, Clinica Universidad de Navarra, 31008 Pamplona, Spain; mponz@unav.es \\ 3 IdiSNA, Navarra Institute for Health Research, 31008 Pamplona, Spain \\ 4 Department of Gastroenterology, Hepatology, and Endocrinology, Hannover Medical School, \\ 30625 Hannover, Germany; saborowski.michael@mh-hannover.de (M.S.); \\ vogel.arndt@mh-hannover.de (A.V.) \\ 5 Institute for Pathology, Regensburg University, 93053 Regensburg, Germany; \\ Diego.Calvisi@klinik.uni-regensburg.de \\ 6 Centro de Investigación Biomédica en Red de Cáncer (CIBERONC), 28029 Madrid, Spain \\ * Correspondence: saborowski.anna@mh-hannover.de (A.S.); silvevicent@unav.es (S.V.); \\ Tel.: +49-511-532-9590 (A.S.); +34-948194700 (ext. 812029) (S.V.) \\ + These authors share senior authorship.
}

Received: 14 November 2019; Accepted: 22 November 2019; Published: 26 November 2019

check for updates

\begin{abstract}
Cholangiocarcinoma (CCA) is a genetically and histologically complex disease with a highly dismal prognosis. A deeper understanding of the underlying cellular and molecular mechanisms of human CCA will increase our current knowledge of the disease and expedite the eventual development of novel therapeutic strategies for this fatal cancer. This endeavor is effectively supported by genetic mouse models, which serve as sophisticated tools to systematically investigate CCA pathobiology and treatment response. These in vivo models feature many of the genetic alterations found in humans, recapitulate multiple hallmarks of cholangiocarcinogenesis (encompassing cell transformation, preneoplastic lesions, established tumors and metastatic disease) and provide an ideal experimental setting to study the interplay between tumor cells and the surrounding stroma. This review is intended to serve as a compendium of CCA mouse models, including traditional transgenic models but also genetically flexible approaches based on either the direct introduction of DNA into liver cells or transplantation of pre-malignant cells, and is meant as a resource for CCA researchers to aid in the selection of the most appropriate in vivo model system.
\end{abstract}

Keywords: cholangiocarcinoma; biliary tract; hydrodynamic injection; genetically-engineered mice; in vivo models

\section{Introduction}

Cholangiocarcinoma (CCA) is the most prevalent biliary neoplasm and the second most frequent liver tumor after hepatocellular carcinoma (HCC), accounting for 10-20\% of cancer-related deaths due to hepatobiliary malignancies [1,2]. CCA involves a heterogeneous group of cancers arising from the biliary tree that can be classified based on their anatomical location as intrahepatic (iCCA), perihiliar (pCCA) and distal (dCCA) [3,4]. Biliary inflammation is the common denominator of several risk factors identified thus far, such as primary sclerosing cholangitis, infestation with liver flukes, hepatitis $\mathrm{C}$ or B virus infection, chronic alcohol abuse, and non-alcoholic steatohepatitis. Most CCAs, however, are considered sporadic and arise in the absence of evident risk factors. 
Surgical resection remains the only potentially curative therapeutic option, but only one-third of patients qualify for surgery at the time of diagnosis and early recurrence worsens the prognosis. Since the disease frequently remains clinically silent for a long time, most patients are bound to receive palliative treatments from initial diagnosis onwards. Based on the results from the ABC-02 trial, the standard chemotherapeutic regimen consists of gemcitabine in combination with cisplatin, leading to a median overall survival of 11.7 months with a median progression-free survival of 8 months [5]. Retrospective analyses regarding the use of second line treatments have been inconclusive and, thus far, no second line treatment recommendations exist, further emphasizing the imperative need for novel and more effective therapeutic strategies.

The molecular landscape of cholangiocarcinoma is heterogeneous and segregates with the anatomical location as well as the underlying risk factors. Based on the results from recent sequencing studies, an extensive catalogue of genetic alterations exists, including oncogenic activation of $K R A S$, or inactivating mutations in tumor suppressor genes (TSGs) such as TP53, CDKN2A/B, SMAD4 and PTEN, as well as in DNA repair genes (e.g., BRCA) and epigenetic modifiers such as ARID1A. Notably, in about $30-40 \%$ of CCA patients, molecularly targetable alterations exist, indicating that precision medicine may be beneficial in a considerable subset of biliary tract cancers. Indeed, several of such "targeted" agents have already been tested within the framework of clinical trials, including FGFR inhibitors in patients with FGFR2 fusions, IDH inhibitors in patients with IDH1/2 mutations, and BRAF/MEK inhibitors in patients with activating $B R A F$ mutations. Despite the increasing number of clinical trials, the early positive signals for precision medicine and an expanding "toolbox" for the treatment of CCA patients, we are still lacking a "deeper" understanding of those complex mechanisms that lead to the development of biliary cancer and determine the response or resistance to therapy.

As the genetic annotation of human cancer evolved, a plethora of genetically engineered murine models of cancer have been developed, which have since then served as pre-clinical platforms that allow us to study the disease in the context of a clinically relevant, intact microenvironment. With the increasing clinical and scientific recognition of biliary tract cancers, a repertoire of murine model systems for CCA has been developed in recent years and is now at our disposal to choose from. Considering the heterogeneity of the disease and the vast array of open questions regarding CCA pathophysiology, it is highly unlikely, though, that one single model will serve as "the ultimate", universal pre-clinical tool. In this review, we will discuss a selection of murine models that have the potential to accelerate CCA research, expand our current knowledge about this cancer and, eventually, unveil novel opportunities to build better treatment strategies.

\section{Genetic Mouse Models of CCA}

Various genetic mouse models that portray the ample catalogue of mutations found in human CCA have been developed for the characterization of different stages of cholangiocarcinogenesis, ranging from the neoplastic transformation of normal liver or biliary cells to CCA progression and metastasis. In general, these models are based on three distinct genetic approaches: (1) somatic gene transfer into adult liver cells by hydrodynamic tail vein injection, liver electroporation, or adeno-associated virus (AAV) in vivo transduction (2) the manipulation of mouse embryonic stem cells to generate genetically-engineered mice, or (3) transplantation of pre-malignant cells, such as genetically engineered fetal liver cells or biliary organoids.

\section{Somatic Gene Transfer Models}

\subsection{Hydrodynamic Tail Vein Injection (HTVI) Models}

HTVI models are based on the delivery of plasmid DNA into hepatocytes by means of high-volume injection: controlled hydrodynamic pressure in capillaries enhances the permeability of endothelial and parenchymal cells, allowing DNA to enter the cells through the transient opening of "pores" in the plasma membrane (reviewed in [6]). Through the incorporation of the Sleeping Beauty transposon 
toolbox to the hydrodynamic injection technique, stable integration of transgenes can be achieved in several tissues $[7,8]$. Notably, the liver is particularly prone to plasmid DNA incorporation and HTVI efficiently targets up to $10 \%$ of liver cells. Therefore, several groups have adopted this technology for the generation of mouse models of liver carcinogenesis based on the introduction of genetic alterations found in the human counterparts [9].

HTVI models pose a series of advantages for in vivo studies. First, since only a fraction of hepatocytes is targeted by HTVI, normal and transformed cells coexist in the autochthonous environment, thus mimicking the human setting. Second, given that recipient mice are 6-8 weeks old, tumors develop in an adult organism, as is most commonly the case in humans. Third, many HTVI models form tumors very rapidly (1-2 months), thereby accelerating experimental readout. The main limitation of this method is the fact that HTVI delivers genes exclusively into hepatocytes of the pericentral region (zone 3 of the liver acinus). Therefore, a transdifferentiation stimulus, likely induced by the respective transgenic driver, is needed to facilitate CCA-like histologies, and studies aimed at investigating the role of hepatic stem cells or biliary epithelial cells to CCA carcinogenesis are not possible using this approach. Furthermore, all HTVI studies focus on CCA initiation, i.e., to understand the role of CCA-relevant genes in cancer formation, but not in progression and metastasis. Lastly, in contrast to what is frequently observed in the human situation, tumors in conventional HTVI models develop in the absence of an inflammatory microenvironment, which limits their applicability for studies of tumor-stroma crosstalk. Table 1 summarizes the HTVI models of CCA described to date, with some of the most representative and/or time-efficient models discussed in more detail.

Table 1. Genetic models based on liver transgene delivery. Summary of CCA models based on transgene delivery via HTVI or liver electroporation. iCCA: intrahepatic CCA; eCCA: extrahepatic CCA; HCC: hepatocellular carcinoma.

\begin{tabular}{|c|c|c|}
\hline \multicolumn{3}{|c|}{ Somatic Gene Transfer Delivery Models } \\
\hline Transgene and Mouse Genetic Background & Key Features & Reference \\
\hline NRasV12 in Ink4A/Arf ${ }^{-1-}$ mice & Development of mixed HCC/iCCA 4-6 weeks after HTVI & [10] \\
\hline Yap and $P I 3 K C A$ in wt mice & $\begin{array}{l}\text { HCC }(\sim 40 \%), \text { CCA }(\sim 10 \%) \text {, and mixed HCC/iCCA }(\sim 50 \%) \\
\text { formation. iCCAs cover } \sim 80 \% \text { of the liver parenchyma } \\
\text { within } 12-13 \text { weeks post-HTVI }\end{array}$ & [11] \\
\hline NICD1 in wt mice & $\begin{array}{l}\text { HTVI induces formation of cystic cholangiocellular tumors } \\
\text { resembling human biliary cystadenomas by } 20 \text { weeks }\end{array}$ & [12] \\
\hline NICD 1 and $A K T$ in wt mice & $\begin{array}{l}\text { Quick formation of iCCA ( } 4.5 \text { weeks after HTVI) with signs } \\
\text { of malignancy such as high content of mitotic figures, } \\
\text { necrosis and invasion of the liver parenchyma }\end{array}$ & [12] \\
\hline MyrAKT and $Y A P(\mathrm{~S} 127 \mathrm{~A})$ in wt mice & Quick (3 weeks post-HTVI) model of iCCA & {$[13]$} \\
\hline MyrAKT and NRAS (V12D) in wt mice & Quick (3 weeks post-HTVI) model of mixed HCC/iCCA & {$[14-16]$} \\
\hline NICD in Kras ${ }^{\text {LSL-G12D }}$ mice & $\begin{array}{l}\text { Tumors of ductal and cystic morphology with variable } \\
\text { amount of desmoplastic stroma invading the surrounding } \\
\text { hepatocellular parenchyma } 8 \text { weeks after HTVI }\end{array}$ & [17] \\
\hline Overexpression of $J a g 1$ and $A K T$ in wt mice & $\begin{array}{l}\text { Tumors of solid, ductular or cystic differentiation with some } \\
\text { stroma development } 8 \text { weeks after HTVI. Exclusively iCCA }\end{array}$ & [18] \\
\hline NICD, YAP and Tp53 shRNA & $\begin{array}{l}\text { HCCs or iCCAs form } 6 \text { weeks post-HTVI in response to Wnt } \\
\text { and Notch signaling respectively Nestin-positive } \\
\text { progenitor-like cells (from de-differentiated mature } \\
\text { hepatocytes) upon Tp53 loss }\end{array}$ & [19] \\
\hline Myc and Nras or Myc and $A K T$ & $\begin{array}{l}\text { HTVI delivery induces HCC, while delivery of the same } \\
\text { oncogenes by electroporation forms stroma-rich iCCA (both } \\
\text { by models develop by } 4 \text { weeks after transgene delivery) }\end{array}$ & {$[20]$} \\
\hline Cas9, Cre and sgRNAs in Kras ${ }^{\mathrm{LSL}-\mathrm{G} 12 \mathrm{D} /+}$ mice & $\begin{array}{l}\text { Formation of HCC and iCCA } 20-30 \text { weeks after delivery } \\
\text { via HTVI }\end{array}$ & [21] \\
\hline Cas9 and sgRNAs to Pten and Tp53 & $\begin{array}{l}\text { Liver tumors featuring bile duct differentiation markers } \\
\text { (CK19 positive) by } 12 \text { weeks post-HTVI }\end{array}$ & [22] \\
\hline
\end{tabular}


Table 1. Cont.

\begin{tabular}{ll}
\hline \multicolumn{2}{c}{ Somatic Gene Transfer Delivery Models } \\
\hline Transgene and Mouse Genetic Background & \multicolumn{1}{c}{ Key Features } \\
\hline $\begin{array}{l}\text { AKT and YAP plus IL-33 intraperitoneal } \\
\text { injection }\end{array}$ & $\begin{array}{l}\text { Overexpression in biliary cells induces CCA formation along } \\
\text { the biliary system 10 weeks after HTVI. IL-33 increases } \\
\text { penetrance. Likely technically adaptable for } \\
\text { eCCA formation. }\end{array}$ \\
\hline$K R A S^{G 12 V}$ in $T p 53^{\mathrm{f} / \mathrm{f}}$ & $\begin{array}{l}\text { Quick (3-5 weeks) model based on liver electroporation of } \\
\text { KRAS (G12V) induces single nodule iCCA formation }\end{array}$ \\
\hline
\end{tabular}

\subsubsection{RAS-Driven HTVI Models}

In 2005, the Largaespada's lab provided the proof-of-concept that transposon technology can be used to study liver tumorigenesis [10]. In the first example of an HTVI liver cancer model, exogenous expression of NRAS oncogene (G12V) in $A r f^{-/-}$mice gave rise to an early onset of multiple nodular tumors 4 to 6 weeks after transfection. Tumor latency doubled in heterozygous $A r f^{+/-}$ mice, highlighting the importance of the genetic background of recipient mice in liver carcinogenesis. Importantly, both HCC- and iCCA-like tumors arose in this model. Thus, the application of this liver cancer model to exclusively study CCA pathobiology is limited.

Another HTVI-based study modeling the consequences of RAS-driven carcinogenesis was later described by Zhang et al. Here, hydrodynamic injection of NRAS (G12V) and a constitutively active form of $A K T$ (myrAKT) also yielded HCC and iCCA in mice 3 to 4 weeks after injection [14]. Interestingly, a latter version of the model incorporated the genetic ablation of FASN, the master regulator of fatty acid synthesis, whose expression is upregulated in human HCC samples but is frequently low in human iCCA specimens. Upon administration of a Cre recombinase transgene simultaneously with NRAS and $A K T$ in $\mathrm{Fasn}^{\text {flox/flox }}$ mice, developing tumors exhibited nearly exclusively iCCA differentiation, highlighting the dependency of HCC—but not CCA—on de novo lipid synthesis [15].

\subsubsection{NOTCH-Driven HTVI Models}

One of the most rapid models of iCCA, which displays human CCA features such as high mitotic activity, invasion of the surrounding liver parenchyma and necrosis, was reported in 2012. Based on the frequent activation of NOTCH signaling found in human CCA, Fan et al. overexpressed the intracellular domain of the NOTCH1 receptor (NICD) that shuttles from the membrane to the nucleus to function as a pro-oncogenic transcriptional regulator. Single administration of NICD transgene yielded CCA-like lesions exhibiting initial features of malignant transformation with a latency of 20 weeks. Notably, concomitant transfection of NICD and AKT significantly accelerated tumor development and led to formation of similar lesions with a latency of only 3.5 weeks that progressed rapidly and occupied most of the liver parenchyma by 5 weeks [12]. Paralleling this approach, transposon-based delivery of NICD and Cre-recombinase into genetically engineered mice harboring the latent mutant $\mathrm{Kras}$ allele ( $\left.\mathrm{Kras}^{\mathrm{LSL}-\mathrm{G} 12 \mathrm{D}}\right)$ gave rise to liver tumors closely resembling human CCA by 8 weeks post-transfection [17].

Upstream activation of NOTCH signaling can occur through the NOTCH ligand JAG1, which is frequently upregulated in human CCA. Further supporting the decisive effects of NOTCH signaling on cholangiocarcinogenesis, concomitant delivery of myrAKT1 together with JAG1 induces exclusively iCCA formation, but not HCCs, by 8 weeks post-transfection [18].

A conceptually similar HTVI model took advantage of Yes-associated protein (YAP) overexpression. YAP, a major downstream effector of Hippo-signaling, is considered to act as an oncogenic driver in HCC and is also active in CCA [25]. Notably, YAP can positively regulate JAG1 expression [26], providing a direct link to NOTCH signaling. Concomitant YAP and myrAKT transgene overexpression led to activation of PI3K and RAS signaling, as well as an enhanced activity of the glycolytic pathway, resulting in early iCCA formation within 3 weeks post-transfection and death of tumor-bearing mice between 5.5 and 7.5 weeks. MTORC1 and mTORC2 are key downstream signaling components of 
AKT activation. Notably, while knockdown of mTORC1 significantly delayed tumor development, genetic abrogation of mTORC2 not only delayed tumor onset, but also led to the development of tumor lesions with hepatocellular -instead of cholangiocellular- differentiation [13].

As a second transposon-based HTVI model that featured YAP as a co-oncogenic driver, Li et al. simultaneously delivered active-mutant forms of YAP (S127A) and PIK3CA (H1047R) into the mouse liver, which resulted in the formation of liver tumors by approximately 12 to 13 weeks post-delivery. In this model, tumor histology ranged from HCC $(40 \%)$ and iCCA $(10 \%)$, to mixed HCC/iCCA (50\%) [11]. Overall, the differences observed through overexpression of distinct elements within the same signaling pathways reinforce the idea that a precise selection of transgenes is critical to steer the development of appropriate HTVI models of CCA.

As a note of caution concerning the generalization of the reported latencies and histological presentations, it cannot be excluded that tumor kinetics as well as histological presentation may, in part, be dependent on the strain background and/or the gender of the "recipient" mouse.

\subsubsection{CRISPR-Cas9-Based HTVI Approaches}

In recent years, the genome-editing field has been extraordinarily transformed by the bacterial RNA-guided clustered regularly interspaced palindromic repeat (CRISPR)-Cas9 system. The CRISPR-Cas9 technology provides an efficient method for somatic gene editing of cancer-related genes, both to generate functional knockouts (by the introduction of insertion or deletions-indels-in specific genes) and to recreate driver mutations (by homology-directed repair) [27]. Pioneering work by Xu et al. in 2014 illustrated that HTVI and CRISPR-Cas9 approaches could be successfully combined for the study of intrahepatic tumors. Hydrodynamic administration of single guide RNAs (sgRNAs) to target the TSGs Tp53 and Pten in wild-type FVB mice originated tumors of biliary differentiation 3 months after injection, faithfully recapitulating the liver lesions found in adeno-Cre-activated, Tp53 $3^{\text {flox/flox }} ;$ Pten ${ }^{\text {flox/flox }}$ mice [22].

One step further, the Rad lab took advantage of the CRISPR-Cas9 technology to perform a multiplexed in vivo mutagenesis screen in order to identify biologically relevant TSGs involved in liver cancer formation. A pool of $10 \mathrm{sgRNAs}$ was injected together with a Cre recombinase transgene into Alb-Cre; Kras ${ }^{\mathrm{LSL}-\mathrm{G} 12 \mathrm{D} /+}$ mice, resulting in the formation of multifocal liver tumors of HCC and iCCA histology 20 to 30 weeks after injection. Next generation sequencing (NGS) and comparative genomic hybridization (CGH) detected no off-target effects in CRISPR-Cas9 induced liver tumors, highlighting the accuracy of the gene editing strategy [21]. Given the wealth of genomic information from NGS efforts, this study provides the experimental platform to quickly and efficiently screen biological functions of newly identified CCA-related gene sets. Collectively, these two studies demonstrate that HTVI and CRISPR-Cas9 approaches are complementary tools for the development and investigation of CCA genetic models.

\subsection{Liver Electroporation Models}

Liver electroporation is an alternative technique for efficient hepatic gene delivery. Following laparotomy, the liver is exposed, plasmids are injected into the parenchyma, and an electric pulse is applied at the injection site. In contrast to HTVI approaches, which generally lead to the development of multiple tumor nodules across the liver, liver electroporation generates mostly focal tumors at the site of the electroporation.

A pioneer study by Gurlevik et al. demonstrated that Sleeping Beauty-mediated expression of $\mathrm{Kras}^{\mathrm{G} 12 \mathrm{~V}}$ in $p 53^{\mathrm{f} / \mathrm{f}}$ mice efficiently leads to iCCA development through the transdifferentiation of hepatocytes. Additionally, this study highlighted the utility of the model to address adjuvant treatment strategies after R0 resection [24].

More recently, in 2018, Seehawer et al. reported significant differences in the histology of liver tumors formed when identical sets of oncogenes were introduced into hepatocytes by HTVI or liver electroporation techniques. Co-expression of oncogenic $\mathrm{Myc}$ and $\mathrm{Nras}{ }^{\mathrm{G} 12 \mathrm{~V}}$, or $\mathrm{Myc}$ and $A K T 1$ gave rise 
to multifocal liver carcinomas with HCC histology when introduced using HTVI, whereas, upon liver electroporation, the same combination of oncogenes resulted in focal iCCA or combined iCCA-HCC development. The authors went on to show that the surrounding hepatic microenvironment determines the cell fate of liver tumors, revealing that, in transformed hepatocytes containing the same oncogenic drivers, neighboring hepatocytes undergoing apoptosis induce the formation of $\mathrm{HCC}$, while surrounding necroptotic hepatocytes determine CCA outgrowth [20]. Thus, this study highlights the importance of epigenetic cues from the tumor microenvironment in shaping the "phenotypic" differentiation of liver tumors.

\subsection{Intrabiliary Transfection of DNA}

As discussed earlier, the development of new CCA models based on the HTVI as well as the liver electroporation approach is compromised by the delivery of transgenes into hepatocytes, but not into cholangiocytes. To circumvent this limitation, a novel model that facilitates the direct transfection of biliary cells by intrabiliary injection coupled with lobar bile duct ligation was recently described by Yamada et al. Introduction of $A K T$ and YAP transgenes into biliary cells led to CCA development in $20 \%$ of mice 10 weeks after in vivo transfection. Penetrance of tumor development could be further increased to $72 \%$ through an IL-6 dependent mechanism upon intraperitoneal injection of the biliary mitogen IL-33 [23]. The authors emphasized that tumor formation is not restricted to specific locations within the biliary tree. Therefore, despite photographs from the publication suggesting that most tumors arose as intrahepatic CCA, it appears likely that the approach could be adapted to generate extrahepatic CCAs (eCCAs). Although technically challenging, this model offers new opportunities for the generation of CCA mouse models by transposon-based gene delivery to the biliary epithelium and, considering the IL6-dependent increase in tumor formation, somewhat recapitulates the tumor-promoting role of inflammatory cues from the microenvironment.

\section{Genetically Engineered Mouse (GEM) Models}

GEM models are widely considered the most sophisticated animal models of human cancer. In these autochthonous cancer models, tumor initiation occurs de novo under the tight control of specific genetic modifications [28,29]. To date, multiple GEM models exist that faithfully recapitulate many histopathological features of human cancers, from early transformation stages to metastasis. Moreover, GEM models share molecular features with human cancers, as already illustrated in pioneering studies based on cross-species comparison analyses [30-32]. Since then, almost any GEMs, including those representative of CCA, have been investigated for their cellular and molecular similarities with their human cancer counterpart. For these reasons, GEM models have been incorporated as in vivo platforms for the rationale testing of standard-of-care chemotherapies and/or novel targeted agents [33].

GEM models of CCA developed to date incorporate many of the frequent oncogenic alterations found in humans [34-39], thus tightly mirroring the molecular events driving cholangiocarcinogenesis. A key advantage of these models is the development of tumors within the context of a complex organism. Additionally, the spectrum of preneoplastic, early and late tumor stages (including metastasis) in a highly reproducible setting enables the interrogation of critical aspects of carcinogenesis. However, the generation of new GEM strains requires complex and time-consuming breeding strategies, and tumor latency is relatively long in most cases, which translates into a significant economical investment. Unlike in humans, expression of the respective genetic alterations already occurs during embryogenesis in most non-inducible GEM models, although newly developed mouse strains aid to circumvent this problem. For instance, the incorporation of tamoxifen inducible, organ-specific Cre-recombinase-encoding alleles allows activation of latent alleles on demand in adult organisms. Further, hepatocyte-specific activation/incorporation of transgenes in GEM models can be easily achieved through incorporation of in vivo transfection techniques (HTVI and/or electroporation, described above), but also by using adeno-associated-virus-based AAV8 vectors. Intravenous injection of AAV8 vectors achieves efficient transgene delivery to hepatocytes, and additional specificity can be secured by using liver-specific 
promoters to drive transgene expression. Beyond the relative organ specificity, the use of endogenous promoters to drive transgene expression may more closely recapitulate physiological expression levels of the transgene in the host organism. Table 2 provides a summary of CCA GEM models reported to date, with a more detailed description of some key approaches found below.

Table 2. Genetically engineered mice (GEM) and GEM-derived models. Summary of GEM models and additional mouse models developed based on existing GEM. iCCA: intrahepatic CCA; eCCA: extrahepatic CCA; HCC: hepatocellular carcinoma.

\begin{tabular}{|c|c|c|}
\hline \multicolumn{3}{|c|}{ GEM and GEM-Derived Models } \\
\hline Genetic Strategy & Key Features & Reference \\
\hline Alb-Cre, Smadf flox/flox,$P t e n^{\text {flox/flox }}$ & $\begin{array}{l}\text { Liver progenitor cells (LPCs) iCCA development } \\
\text { involving a multistep sequence including hyperplasia, } \\
\text { dysplasia, carcinoma in situ and well-established CCA. } \\
\text { Tumor latency: } 4-7 \text { months }\end{array}$ & {$[40]$} \\
\hline AhCre ${ }^{\mathrm{ERT}}, \mathrm{Kras}^{\mathrm{V} 12 /+}$, Pten $^{\text {flox/flox }}$ & $\begin{array}{l}\text { Oncogenic events in biliary epithelium yield multifocal } \\
\text { non-invasive papillary neoplasms in the intrahepatic } \\
\text { biliary tract involving both major interlobular bile ducts } \\
\text { and small bile duct radicles in portal tracts. Mice survive } \\
\text { up to } 43 \text { days }\end{array}$ & {$[41]$} \\
\hline Alb-Cre, Kras ${ }^{\text {LSL-G12D/+ }}$, Pten $^{\text {flox/flox }}$ & $\begin{array}{l}\text { Highly invasive and desmoplastic CCA originated from } \\
\text { LPCs, with a glandular morphology that resembles } \\
\text { well-differentiated human CCA. Tumors form by } 4 \text { weeks }\end{array}$ & {$[42,43]$} \\
\hline Alfp-Cre; Tp53 flox/flox & $\begin{array}{l}\text { Loss of p53 in LPCs leads to formation of advanced HCC } \\
\text { and iCCA. Tumor formation in 14-20-month-old mice }\end{array}$ & {$[44]$} \\
\hline $\begin{array}{l}\text { Alb-Cre; Kras }{ }^{\mathrm{LSL}-\mathrm{G} 12 \mathrm{D} /+} ; \\
\quad \text { Tp } 53^{\text {flox/flox }}\end{array}$ & $\begin{array}{l}\text { Tumors of iCCA }(66 \%) \text {, HCC }(17 \%) \text { and HCC/iCCA } \\
(17 \%) \text { histology. iCCA with multistage progression } \\
\text { including stroma-rich tumors, premalignant biliary } \\
\text { lesions (IPNB and VMC) and metastasis. Tumors form as } \\
\text { early as } 9 \text { weeks }\end{array}$ & {$[45]$} \\
\hline $\begin{array}{c}\text { Sox9-Cre } e^{\text {ERT2+ }} ; \text { Kras }^{\text {LSL-G12D/+ }} \\
\text { Tp5 } 53^{\text {flox/flox }}\end{array}$ & $\begin{array}{l}\text { Development of iCCA tumors accompanied by adjacent } \\
\text { extensive ductular reactions and desmoplasia, as well as } \\
\text { areas resembling biliary intraepithelial neoplasia (BIN). } \\
\text { Tumor latency: } 30 \text { weeks }\end{array}$ & {$[46]$} \\
\hline $\operatorname{Kras}^{\mathrm{LSL}-\mathrm{G} 12 \mathrm{D} /+} ; \operatorname{Tp} 53^{\text {flox/flox }}$ & $\begin{array}{l}\text { Mice infected with an adeno-associated virus expressing } \\
\text { Cre (AAV-TBG-Cre) develop iCCA }(40 \%) \text {, HCC }(40 \%) \text {, } \\
\text { mixed HCC/iCCA }(20 \%) \text {. Tumors form between } 12-\text { and } \\
66 \text {-weeks post-injection }\end{array}$ & {$[46]$} \\
\hline $\begin{array}{l}\text { Alb-Cre; Kras }{ }^{\mathrm{LSL}-\mathrm{G} 12 \mathrm{D} /+} \\
\text { Fbxw }\end{array}$ & $\begin{array}{l}\text { Dysplastic dust-like structures surrounded by fibrosis (at } \\
8 \text { months, some heterozygous Fbxw } 7^{\text {LSL-R468C }} \text { mice show } \\
\text { bile duct dilation and hyperplasia). }\end{array}$ & {$[47]$} \\
\hline $\begin{array}{l}\text { Alb-Cre; IDH2 } 2^{\text {LSL-R172K, }} \\
\quad \text { Kras }^{\text {LSL-G12D }}\end{array}$ & $\begin{array}{l}\text { All mice develop multifocal liver masses of iCCA } \\
\text { histology. Tumor latency: } 33-58 \text { weeks }\end{array}$ & {$[48]$} \\
\hline Alb-Cre; NotchICD & $\begin{array}{l}\text { Transplantation of liver cells from } 8 \text { months-old mice in } \\
\text { immunodeficient animals produces iCCA, likely derived } \\
\text { from progenitor cells. Tumor latency: } 8 \text { months }\end{array}$ & {$[49]$} \\
\hline Alb-Cre; Tp53flox/flox $;$ NotchICD & $\begin{array}{l}\text { iCCA with abortive glandular pattern (moderate to high } \\
\text { pleomorphic nuclei with some atypical mitoses) } \\
\text { developed along with a dense fibrous tissue with } \\
\text { inflammatory cells. Tumors form by } 6 \text { months }\end{array}$ & {$[50]$} \\
\hline Alb-Cre; Hspd1 $1^{\text {flox/flox }}$ & $\begin{array}{l}\text { Lesions of cholangiocellular histology, characterized by } \\
\text { irregular glands, loss of polarity, multilayering of cells, } \\
\text { and frequent mitosis resembling human BIN, form by } \\
4-6 \text { weeks }\end{array}$ & {$[51]$} \\
\hline $\begin{array}{c}\text { K19 }{ }^{\text {CreER }} ; \text { Kras }^{\text {LSL-G12D/+ }} \\
\text { Tgfßr } 2^{\text {flox/flox }} \text { and } C d h 1^{\text {flox/flox }}\end{array}$ & $\begin{array}{l}\text { Swollen gallbladder including invasive periductal } \\
\text { infiltrating type eCCA metastasizing to lymphatic } \\
\text { vessels and a prominently thickened EHBD wall. Mice } \\
\text { die at } 4 \text { weeks of age }\end{array}$ & {$[52]$} \\
\hline
\end{tabular}


Table 2. Cont.

\begin{tabular}{|c|c|c|}
\hline \multicolumn{3}{|c|}{ GEM-based allograft models } \\
\hline Genetic Strategy & Key Features & Reference \\
\hline 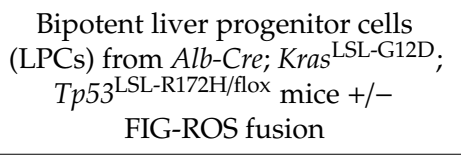 & $\begin{array}{l}\text { Implanted LPCs give rise to liver tumors with advanced } \\
\text { iCCA features. Median overall survival of Alb-Cre; } \\
\text { Kras } \\
79 \text { day-G12D; Tp53 } 5 \text { LSL-R172H/flox tumor-bearing mice: }\end{array}$ & [53] \\
\hline $\begin{array}{l}\text { Bipotent or cholangiocytic } \\
\text { progenitor cells or hepatocytes } \\
\text { from } T p 53^{-/-} \text {mice }\end{array}$ & $\begin{array}{l}\text { Tumors with mixed hepatocytic and cholangiocytic } \\
\text { differentiation embedded in a prominent stroma. Tumors } \\
\text { form between } 30 \text { and } 120 \text { days after cell inoculation }\end{array}$ & [44] \\
\hline $\begin{array}{l}\text { Adult liver organoids from } \\
\text { Kras }^{\text {LSL-G12D }} ; \text { Tp53 flox/flox mice } \\
\text { after Cre-activation in vitro }\end{array}$ & $\begin{array}{l}\text { Kras driven tumors lead to CCA formation, while } \\
\text { expression of c-Myc in wild-type organoids drives HCC } \\
\text { formation. Tumor latency for Cre- activated Kras }{ }^{\text {LSL-G12D }} \\
\text { Tp53 } 3^{\text {flox/flox }} \text { 6-8 weeks }\end{array}$ & [54] \\
\hline \multicolumn{3}{|c|}{ Carcinogen-treated GEM models } \\
\hline $\begin{array}{l}\text { Alb-Cre } e^{\mathrm{ERT} 2} ; R 26^{\mathrm{RlacZ} /+} \text { and } \\
\text { Ck19-Cre }{ }^{\mathrm{ERT} 2} ; R 26^{\mathrm{RlacZ} /+} \text { mice } \\
\text { treated with TAA }\end{array}$ & $\begin{array}{l}\text { Liver cirrhosis containing cells with the typical histology } \\
\text { of iCCA }\end{array}$ & [55] \\
\hline $\begin{array}{l}\text { Ck19-Cre }{ }^{\mathrm{ERT} / \mathrm{eYFP}} ; \mathrm{Tp} 53^{\text {flox/flox }} \text { mice } \\
\text { treated with TAA }\end{array}$ & $\begin{array}{l}\text { Formation of multifocal invasive iCCA. Tumors appear } \\
\text { after } 26 \text { weeks }\end{array}$ & [56] \\
\hline $\mathrm{Tp} 53^{-/-}$mice treated with $\mathrm{CCl} 4$ & $\begin{array}{l}\text { Development of injury/necrosis, proliferation and } \\
\text { fibrosis in bile duct after } 4 \text { months of treatment }\end{array}$ & [57] \\
\hline
\end{tabular}

\subsection{Loss of Smad4 and Pten Tumor Suppressor Genes}

In 2006, Xu et al. developed the first GEM model of CCA. Combined ablation of liver-specific Pten and Smad4, two mutations commonly found in human CCA [34-36], was obtained by crossing mice harboring the conditional alleles for each TSG to the Albumin Cre (Alb-Cre) strain [40]. The Alb-Cre strain allows recombination of the loxP sites in adult hepatocytes as well as in liver precursor cells of hepatocytes and cholangiocytes during embryonic development [58]. In the Alb-Cre; Smad4 ${ }^{\text {flox/flox; }}$ $P t e n^{\text {flox/flox }}$ model, hyperplastic foci arose from bile ducts at 2 months, and all mice developed iCCA between 4 and 7 months of age. Thus, the model preserves the gradual progression from bile duct hyperplasia and dysplasia to carcinoma in situ and invasive CCA that is frequently seen in the human situation. Similar to HTVI models, activation of the PI3K-AKT-mTOR pathway led to the expected phosphorylation of downstream targets, such as AKT, FOXO1, mTOR and GSK3 $\beta$. Additionally, hyperactivation of p-ERK and overexpression of cyclin D1 was observed. Finally, the authors showed a reciprocal regulation of Pten and Smad4 to maintain an expression balance to suppress CCA, thus highlighting the importance of the dual inhibition during CCA development in this model.

\subsection{Simultaneous Activation of Kras and Deletion of Tp53}

KRAS and TP53 mutations are two of the most frequent genetic events in human CCA with prognostic implications for patients [37,39]. In 2012, pioneering studies from the Hezel lab reported the first GEM model with combined Kras activation and Tp53 deletion [45]. In this model, Kras ${ }^{L S L-G 12 D /+}$; $T p 53^{\text {flox/flox }}$ mice were bred to the Alb-Cre mouse strain. Liver tumors developed with full penetrance in 9-week old mice, which succumbed to the disease with a mean survival of 19 weeks. Two thirds of the tumors histologically resembled stroma-rich iCCAs, while the remaining mice developed mixed HCC/iCCA or HCC at a similar frequency (17\% each). The presence of premalignant biliary lesions (intraductal papillary neoplasms -IPNB- and Von Meyenburg complexes -VMC-), indicated that in this model tumors gradually evolve in a stepwise process that phenocopies the human situation, culminating in the progression to invasive carcinoma and the potential to metastasize to distal organs.

As Albumin-Cre is already active during embryonic development in bipotential hepatic progenitors, the cell of origin for iCCA formation in response to activation of Kras and Tp53 remained unclear in this model. To further interrogate whether, in an adult organism, hepatocytes and/or 
cholangiocytes are amenable to Kras/p53 driven malignant transformation, the authors either directed expression of Cre-recombinase towards the biliary compartment by breeding the tamoxifen-inducible, Sox9-Cre ${ }^{\mathrm{ERT} 2+}$ allele into $\mathrm{Kras}{ }^{\mathrm{LSL}-\mathrm{G} 12 \mathrm{D} /+}$; Tp5 $3^{\text {flox/flox }}$ mice, or injected $\mathrm{Kras}{ }^{\mathrm{LSL}-\mathrm{G} 12 \mathrm{D} /+}$; Tp53 $3^{\text {flox/flox }}$ mice with an adeno-associated vector expressing Cre-recombinase under the control of the hepatocyte-specific thyroid-binding globulin promoter (AAV8-TBG-Cre) [59].

AAV-mediated expression of KrasG12D and loss of $T p 53$ in the adult hepatocyte was only sufficient to drive tumorigenesis in this model when combined with an inflammatory stimulus by co-administration of DDC-diet, leading to development of iCCA, but also HCC with a similar incidence, as well as mixed iCCA/HCC tumors. In contrast, more rapid and mostly iCCA development was observed without an additional inflammatory stimulus when the transgenes were activated in the adult ductal compartment upon expression of SOX9-driven Cre-recombinase. Notably, evidence of tumors developing through pre-neoplastic stages was only found in the Sox-9 approach, but not upon DDC treatment [46].

In line with previous reports (e.g., [60]), these results confirm the functional role of Kras and Tp53 in CCA and highlight the influence of liver inflammation on liver cancer formation by priming hepatocytes for oncogenic transformation.

\subsection{Concurrent Activation of Kras and Abrogation of Pten}

A third model incorporating oncogenic Kras was reported by Ikenoue et al. in 2016. Expression of mutant Kras and concomitant deletion of the TSG Pten was targeted to liver cells using the Alb-Cre mouse strain. Active Kras ${ }^{G 12 D}$ synergized with homozygous Pten ablation to form multifocal, stroma-rich intrahepatic iCCA. On average, early hyperplastic biliary foci were detected around four weeks after birth, and mice died after 46 days, making the model one of the fastest CCA GEM models described to date using the Alb-Cre strain [42]. No metastatic lesions were described in this model. Notably, the authors reported that Kras activation in combination with heterozygous Pten deletion developed liver tumors with both hepatocyte and cholangiocyte differentiation, starting at 6 months of age, indicating a dosage-effect of Pten expression. Paralleling the approach by Hill et al. [46], the authors used two additional tamoxifen-regulatable GEM, $\mathrm{Alb}-\mathrm{Cr} e^{\mathrm{ERT2}+}$ or $\mathrm{K} 19 \mathrm{Cr} e^{\mathrm{ERT} /+}$ to activate Kras and delete Pten expression in the adult organism selectively in hepatocytes or cholangiocytes, respectively. However, in this particular model, no inflammatory additional stimulus was introduced. Interestingly, administration of tamoxifen to adult, 8-week old $\mathrm{Alb}-\mathrm{Cr} \mathrm{e}^{\mathrm{ERT} 2+} ; \mathrm{Kras}^{\mathrm{LSL}-\mathrm{G} 12 \mathrm{D}} ; \mathrm{Pten}^{\text {flox/flox }}$ mice lead to the development of HCC and HCC-precursor lesions, but not iCCA, whereas early postnatal tamoxifen injection on day 10 resulted in iCCA. Notably, lineage tracing revealed that, on postnatal day 10, Alb-Cre was still active in biliary cells and, together with the observation that $\mathrm{K} 19 \mathrm{Cr} \mathrm{eRRT}^{\mathrm{ER}+} ; \mathrm{Kras}^{\mathrm{LSL}-\mathrm{G} 12 \mathrm{D}}$; $\mathrm{Pten}^{\text {flox/flox }}$ mice gave rise to pre-malignant papillary ductal lesions in periportal areas, these findings suggest that CCA arises from cholangiocytes in these models. In support of these results, a similar GEM model was recently published by Lin et al., in which most of the previous findings are mirrored [43].

\subsection{Mutations in the IDH Genes}

Mutations in IDH1 and 2 genes occur in approximately 20\% of human CCAs [61,62]. While wild-type IDH is part of the TCA cycle and converts isocitrate to $\alpha$-Ketoglutarate, mutant IDH acquires a neomorphic enzyme activity that results in the aberrant production of 2 Hydroxyglutarate (2-HG) from $\alpha$-Ketoglutarate. Intracellular accumulation of 2-HG blocks hepatocyte lineage progression and inhibits multiple enzymes that utilize $\alpha$-Ketoglutarate as a co-enzyme and are involved in epigenetic regulation [63]. In 2014, Saha et al. developed latent mutant Idh2 (Idh2 ${ }^{\text {LSL-R172K }}$ ) mice that were bred to the Kras ${ }^{\text {LSL-G12D }}$ and Alb-Cre strains to determine the impact of IDH mutations on cholangiocarcinogenesis in the context of mutant Kras. Multifocal liver masses resembling iCCA that exhibited invasive growth patterns and metastatic potential formed in mice ranging from 33 to 58 weeks of age. Oval cell expansion and the presence of biliary intraepithelial neoplasia-like lesions adjacent to tumor foci suggested that the tumors might evolve from such preceding preneoplastic 
stages [48]. Recently, positive phase III data for CCA patients harboring IDH mutations were reported for the IDH inhibitor ivosidenib, emphasizing the direct relevance of such preclinical platforms for "co-clinical trials" to establish mechanisms and biomarkers of response and resistance to the molecularly targeted inhibitors.

\subsection{Activation of the Notch Pathway}

Conceptually similar to the HTVI models mentioned above, Zender et al. investigated the influence of the NOTCH pathway in CCA development using a GEM model. When NICD was expressed under the regulation of $A l b$-Cre, initial features of malignant transformations were present within the liver by the age of 8 months and gave rise to iCCA-like tumors upon transplantation of primary tissues into recipient mice [49]. In contrast, in the HTVI-based NICD overexpression model, tumors formed 20 weeks after introduction of the transgene [12]. The reduced tumor latency might in part be attributable to different levels of transgene expression, an alternate "cell of origin" targeted with the oncogenic driver, as well as strain differences.

\subsection{Mitochondrial Dysfunction}

Mitochondrial dysfunction leads to increased ROS levels and severe liver injury. In a model developed by Yuan et al., this inflammatory environment was induced by the disruption of mitochondrial protein homeostasis in $H s p d 1^{\text {flox/flox }}$ mice crossed to the Alb-Cre strain. Within the severely damaged liver, focal areas of regenerating hepatocytes and cholangiocytes emerged, the latter showing resemblance to human biliary intraepithelial neoplasia. The transgenic animals succumbed to severe liver injury prior to development of fully established iCCA. However, transplantation of liver tissues gave rise to transplantable tumors that histologically showed CCA features.

Notably, most of the regenerating foci observed in the primary livers retained Hspd1 expression, indicating that the lesions evolved in the presence of the injured microenvironment but not through cell-autonomous effects resulting from Hspd1 deletion. Indeed, the authors show that the biliary reaction is the consequence of a Jnk-mediated response to Tumor necrosis factor released from Kupffer cells, triggered by hepatic mitochondrial dysfunction and oxidative stress. While this model does not allow for long-term experiments, due to the premature death of the transgenic animals, it uniquely highlights the fundamental role of the microenvironment in the setting of chronic liver injury, to create a "pre-carcinogenic niche" that promotes tumor development. The non-cell autonomous mechanism that characterizes the development of CCA-precursor lesions in this model contrasts with the cell-autonomous effects primarily involved in oncogene-driven GEM models.

\subsection{Carcinogen-Treated GEM Models}

Administration of carcinogens partially mimics the consequences of an inflammatory environment, a frequent underlying risk factor in the development of human CCA. Integrating carcinogen-induced liver injury and genetically "sensitized" murine models, Farazi et al. combined genetic deletion of Tp53 with administration of the biliary toxin $\mathrm{CCL}_{4}$. In this model, iCCAs developed in the setting of a fibro-inflammatory microenvironment with $50 \%$ penetrance in $\mathrm{Tp} 53^{-/-}$mice and with $18 \%$ in heterozygous Tp53 ${ }^{+-}$mice [57].

A decade later, Guest et al. found that administration of the hepatocarcinogen thioacetamide (TAA) to mice lacking Tp53 in the cholangiocyte compartment, led to the development of iCCA with long latency (>26 weeks) and incomplete penetrance [56]. It is highly likely that co-treatment with carcinogens would also accelerate tumorigenesis in related genetic models of CCA, potentially allowing for a dose-dependent titration of tumor development and a more faithful recapitulation of the pro-inflammatory microenvironment that is considered to influence tumor pathobiology and treatment response. 


\subsection{Extrahepatic CCA}

So far, the different GEM models described above are models of iCCA. In 2017, Nakagawa et al. described the first GEM model of eCCA. Although the K19CreERT mouse strain achieves similar recombination efficiencies across the different portions of the biliary tree, activation of the Kras oncogene and concomitant deletion of the Tgfßr2 and Cdh1 (E-cadherin) in adult K19 positive cells led to CCA development predominantly in the extrahepatic and perihilar bile ducts. The authors provide evidence that the peribiliary glands, located within the walls of the extrahepatic bile ducts, are the site of malignant transformation in this model, resulting in early-onset aggressive tumors metastatic to the regional lymph nodes. Interestingly, the authors show that IL-33, likely released from dying cholangiocytes due to E-cadherin loss, exerts a pro-proliferative stimulus on biliary epithelial cells, thereby actively contributing to malignant transformation. Since K19CreERT is active in the liver and in the lung, most animals die within 4 weeks after tamoxifen administration, due to liver and/or respiratory failure. Therefore, the model is not suitable for long-term experiments. However, the authors show that some of the crucial features of the model can be recapitulated and further followed up using organoids derived from the multiallelic mice [52].

This study highlights how the proper combination of genetic alterations can guide CCA development towards distinct disease subtypes. In conjunction with the $\mathrm{Hspd}^{\text {flox/flox }}$ model of iCCA, these findings further illustrate how genetic events can profoundly influence the surrounding microenvironment to create a pro-inflammatory context that, in turn, exerts deleterious effects on the epithelial liver cells.

\section{Allograft Models}

As an alternative to conventional GEM models, implantation of pre-malignant liver cell populations into recipient mice emerged as a time-efficient approach that circumvents complex and time-consuming breeding schemes.

\subsection{Liver Implantation of Liver Progenitor Cells (LPCs)}

In 2013, we described an allograft CCA mouse model based on the orthotopic implantation of fetal LPCs isolated from Alb-Cre; Kras ${ }^{\mathrm{LSL}-\mathrm{G} 12 \mathrm{D}}$; Tp53 ${ }^{\mathrm{LSL}-\mathrm{R} 172 \mathrm{H} / \mathrm{flox}}$ mice, resulting in the death of recipient animals approximately 3 months after inoculation. Fetal liver cells can be easily further genetically modified, for example through the introduction of retroviral vectors that overexpress oncogene-encoding cDNA cassettes or encode for shRNAs to mimic TSG loss by RNA interference [53].

\subsection{Liver Implantations of CCA Organoids}

Recently, liver organoid technology has evolved as a novel system to model hepatobiliary malignancies [54]. In contrast to LPCs, murine adult liver-derived three-dimensional (3D) organoids can be propagated long-term in vitro and used on-demand, thereby abrogating the need for repetitive isolations of primary cells, while retaining the genetic flexibility of the LPC approach. Organoids can be rapidly engineered using various gene-editing strategies, and transplantation into the livers of syngeneic mice enables tumor growth in an autochthonous and immune-competent microenvironment. Notably, both LPCs and liver organoids retain their plasticity to give rise to both CCA and HCC-like tumors, depending on the genetic context.

\section{Cell Plasticity Leading to CCA: Evidence from Mouse Models}

The lineage tracing approach to identify the cell of origin of a given cancer has been extensively utilized in the last decade $[64,65]$. This approach has been also successfully applied to CCA, with the purpose of unravelling whether these tumors arise from hepatic progenitor cells (HpSC), cholangiocytes, or hepatocytes. Some of the landmark studies on this topic are summarized here. Specifically, a HpSC origin of CCA was suggested in the AlbCre/N2ICD (Notch 2 intracellular domain) model treated with 
the hepatocarcinogen diethylnitrosamine (DEN) [66] as well as in mice overexpressing the active form of Notch1 (AFP-NICD mice) [67]. However, the HpSC origin of CCA has been questioned by tracing the thyroxine-binding globulin in mice subjected to diethylnitrosamine (DEN) and multiple injections of CCl4 or TCPOBOP [68]. Similarly, using a cholangiocyte-lineage tracing system (CK19-lineage tracing) to target p53 loss in biliary epithelia, it was found that the biliary epithelium is in fact the specific target of transformation and origin of iCCA in this model [69]. Nonetheless, the mature hepatocyte has also been identified as the cell of origin of CCA in lineage-tracing studies tracing albumin [51] or transthyretin positive parenchyma cells [12]. In the latter study, the origin of CCA by mature hepatocytes was further confirmed by electron microscopy findings.

The molecular mechanisms driving the transdifferentiation process in the liver, i.e., the capability of a given cell type to convert into a different one, remain to be better elucidated in cholangiocarcinogenesis. These mechanisms presumably implicate the involvement of multiple genetic and epigenetic events, ultimately leading to the activation and interplay of several signaling pathways. Emerging evidence implies a crucial role of the Hippo and Notch pathways in the hepatocyte-to-malignant cholangiocyte conversion $[11,12,14,18,51]$. In particular, it has been shown that iCCA developing in AKT and Yap co-expressing mice derive from mature hepatocyte, and this process is strictly dependent on the canonical Notch2 signaling cascade [13]. Indeed, deletion of Notch2 in AKT/Yap-induced tumors switched the phenotype from iCCA to hepatocellular lesions (adenomas or HCC). In contrast, inactivation of Notch1 in hepatocytes did not lead to any significant histomorphological modification of the original lesions (iCCA) in this model, identifying Notch2 as the major determinant of hepatocyte-derived iCCA [69]. Obviously, further studies are necessary for a better understanding of the transdifferentiation process in CCA.

Although the summarized data are highly helpful to identify the cell of origin of CCA and, thus, to better elucidate the role(s) of the different cell types in cholangiocarcinogenesis, their relevance for the human disease remains to be addressed. Presumably, as shown by the various experimental models, the cell of origin of human CCA may also vary, depending on the oncogenes involved, the type, degree and duration of the pro-oncogenic insults, the status of the liver, etc. In support of this hypothesis, it is worthwhile to mention a paper by Holczbauer et al. [60]. In this study, the authors found that, irrespective of origin, $\mathrm{HpSc}$, lineage-committed hepatoblasts, and differentiated adult hepatocytes transduced with transgenes encoding oncogenic H-Ras and SV40LT acquired markers of stemness, side populations, and self-renewal capacity in vitro. In addition, these transduced cells were also able to form a wide spectrum of liver tumors in vivo, such as CCA and hepatocellular carcinoma (HCC), regardless of the cell of origin. Furthermore, the molecular profiles of each tumor subtype (CCA, HCC, and undifferentiated/mesenchymal-like tumors) were highly similar irrespective of the cell of origin, implying that potentially any cell type in the mouse hepatic lineage might undergo oncogenic reprogramming into a "virtual" HpSC and drive development of CCA and/or other tumor types [60].

\section{Summary}

Genetic mouse models recapitulate many hallmarks of cholangiocarcinogenesis that cannot be modeled using in vitro systems or, even, by xenotransplantation of human CCA cell lines or patient-derived tissue (PDXs) into immunodeficient mice, two alternative in vivo models that have been the focus of comprehensive reviews elsewhere [70,71]. Table 3 highlights the main features of the different in vivo approaches and is intended for the selection of the most adequate model for each study. A particular drawback of any mouse model is the intrinsically high cost of in vivo experiments due to mice number per study, husbandry and maintenance. This issue becomes especially critical in the case of GEM, where breeding schemes can be lengthy, or in those genetic models where tumor latency is significantly longer than in graft models (>two months). 
Table 3. Advantages and disadvantages of in vivo mouse models. Features were rate from best (+++) to worst (-). NA: not available for assessment.

\begin{tabular}{|c|c|c|c|c|c|}
\hline Mouse Model & $\begin{array}{l}\text { Somatic Gene } \\
\text { Transfer }\end{array}$ & GEM & $\begin{array}{l}\text { Implantation } \\
\text { of Mouse Cells }\end{array}$ & $\begin{array}{l}\text { CCA Cells-Based } \\
\text { Xenografts }\end{array}$ & $\begin{array}{l}\text { Patient-Derived } \\
\text { Xenografts }\end{array}$ \\
\hline $\begin{array}{c}\text { Time for tumor } \\
\text { development }\end{array}$ & ++ & \pm & +++ & +++ & + \\
\hline Resource consumption & + & \pm & ++ & ++ & + \\
\hline Technical training & \pm & ++ & ++ & ++ & \pm \\
\hline Ease of maintenance & +++ & + & +++ & +++ & \pm \\
\hline Success rate of initiation & +++ & +++ & +++ & ++ & + \\
\hline $\begin{array}{l}\text { Retention of phenotypic } \\
\text { features }\end{array}$ & ++ & +++ & ++ & \pm & + \\
\hline $\begin{array}{l}\text { Retention of genetic } \\
\text { features }\end{array}$ & +++ & +++ & +++ & ++ & +++ \\
\hline $\begin{array}{l}\text { Representation of genetic } \\
\text { spectrum }\end{array}$ & ++ & +++ & ++ & ++ & + \\
\hline $\begin{array}{c}\text { Amenable to genetic } \\
\text { modification }\end{array}$ & ++ & ++ & +++ & +++ & + \\
\hline $\begin{array}{c}\text { Physiological expression } \\
\text { of transgene }\end{array}$ & \pm & +++ & ++ & ++ & ++ \\
\hline Matched normal controls & +++ & +++ & + & - & \pm \\
\hline $\begin{array}{l}\text { Representation of early } \\
\text { stages of carcinogenesis }\end{array}$ & + & +++ & + & - & - \\
\hline Cell of origin & + & ++ & +++ & - & - \\
\hline Tumor progression & +++ & +++ & +++ & ++ & ++ \\
\hline Tumor-stroma interactions & ++ & +++ & ++ & \pm & + \\
\hline $\begin{array}{c}\text { Immune } \\
\text { microenvironment }\end{array}$ & ++ & +++ & ++ & - & \pm \\
\hline $\begin{array}{l}\text { Chemo-/targeted therapies } \\
\text { studies }\end{array}$ & +++ & +++ & +++ & ++ & +++ \\
\hline Immuno-Oncology studies & ++ & +++ & +++ & - & + \\
\hline
\end{tabular}

A key advantage of genetic mouse models over human cell/tissue-xenografted mouse models, however, is the suitability of murine models to investigate tumor development and tumor-stroma crosstalk within the context of an immunocompetent microenvironment. In traditional transgenic approaches, tumor development can be followed through gradual changes within the epithelial tumor cell compartment, along with a remodeling of the surrounding stroma, thereby allowing researchers to also investigate the early processes of iCCA development within an otherwise intact microenvironment. This "stepwise" tumorigenesis may be only incompletely mirrored in somatic gene transfer and murine allograft model systems. However, these models bear the genetic flexibility to rapidly incorporate additional genetic alterations to functionally annotate potential cancer driver genes in vivo and to characterize them not only regarding their transformative potential, but also concerning their effects on the tumor microenvironment. Furthermore, several models also depend on the consequences of an inflammatory stimulus on tumorigenesis that is derived from the microenvironment itself.

Clearly, no single model will be capable to adequately address all the questions related to cholangiocarcinogenesis. Although the models developed thus far have considerably helped us to better understand important aspects of cholangiocarcinogenesis, at the same time, they have also clearly demonstrated how complex liver tumor formation is. For instance, several of the models can give rise to the full spectrum of liver cancer, from CCA to HCC to mixed tumors. In some of the models, those differences can be traced back to certain engineered genetic alterations within the epithelial tumor cell compartment, to gene dosage, and to microenvironmental cues that influence the 
determination of liver tumorigenesis into biliary or hepatocyte cell lineage differentiation. Similarly, allograft models using primary liver progenitors or organoids can also be directed towards the different lineages of primary liver cancers, depending on the respective cancer drives. When these models are taken seriously, one has to acknowledge that a "dogmatic" approach that tries to establish that "one cell of origin" for CCA may be a misguiding simplification of highly complex mechanisms that guide cellular transdifferentiation and/or neoplastic transformation in the course of liver tumor development.

While the observations that some models lead, in part, to tumors of hepatocellular or mixed differentiation suggests an avenue to their applicability towards understanding tumor "lineage" differentiation, it also indicates how important a thorough a priori characterization of these model systems is in order to adequately use them in translational research. Considering the devastating prognosis and the lack of durable responses, we need accurate pre-clinical systems that can recapitulate the challenges encountered when CCA patients are treated in clinical practice; although effective in selected patient subgroups, precision oncology is hampered by early relapse or insufficient response, despite the presence of targetable genetic lesions. Genetically flexible model systems have the potential to help us to improve our understanding of primary and secondary resistance mechanisms that influence the response to targeted therapies. In addition, these immune-competent in vivo systems may also help us to understand why immune-oncology approaches have thus far failed in CCA and guide us in the implementation of novel therapeutic concepts.

\section{Concluding Remarks}

Although the development of an ideal mouse model for the study of CCA is unrealistic, in part due to the genetic and histological complexity of this tumor, to date, the spectrum of genetic mouse models offers the research community an unprecedented opportunity to elucidate CCA pathophysiology. Currently, the therapeutic portfolio for CCA patients is finally starting to expand considerably: precision medicine is on the verge of becoming an integral component of CCA treatment, and immune-oncology approaches are actively pursued. This development emphasizes the need for immune-proficient, translational model systems in which cancer cell intrinsic and extrinsic mechanisms can be adequately addressed. Based on insights from current clinical trials and integrative molecular profiling studies that imply the existence of several molecular CCA subgroups, it is likely that, within the coming years, the repertory of genetic mouse models will further expand. Building on the "groundwork" that has been laid by the existing approaches, more diversified in vivo systems will be developed, and serve as pre-clinical platforms to address the prevailing questions, from the characterization of the initial steps during cholangiocarcinogenesis, the dissection of histopathological and molecular features, to response and resistance to novel therapeutics.

Author Contributions: A.S. and S.V. conceived the work, designed the outline of the review and supervised all aspects of the manuscript. O.E., A.V. (Adrian Vallejo), M.P.-S., M.S., A.V. (Arndt Vogel), D.F.C. A.S. and S.V. participated in the literature search, scrutiny and interpretation, as well as in writing and editing all contents of the manuscript.

Funding: This research was funded by Departamento de Salud, Gobierno de Navarra: 58/2019; FEDER/Ministerio de Ciencia, Innovación y Universidades-Agencia Estatal de Investigación/SAF2017-89944-R (FEDER/MICIU-AEI/ SAF2017-89944-R); Else Kröner-Fresenius Foundation: 2015_A225; Juan de la Cierva Program (Spanish Ministry of Economy and Competitiveness): FJCI-2017-34233.

Acknowledgments: O.E. was supported by a fellowship by the Juan de la Cierva Program (FJCI-2017-34233) and Adrian Vallejo by ADA of the University of Navarra. S.V. was funded by the Government of Navarra and Fondos FEDER (58/2019), FEDER/Ministerio de Ciencia, Innovación y Universidades-Agencia Estatal de Investigación/SAF2017-89944-R (FEDER/MICIU-AEI/SAF2017-89944-R)) and La Caixa-FIMA agreement. A.S. is supported by the Else Kröner-Fresenius Foundation (2015_A225), and A.S.; M.S. and Arndt Vogel received funding from the SFB/TR 209.

Conflicts of Interest: The authors declare no conflict of interest with respect to the contents of this review. 


\section{References}

1. Rizvi, S.; Gores, G.J. Pathogenesis, diagnosis, and management of cholangiocarcinoma. Gastroenterology 2013, 145, 1215-1229. [CrossRef] [PubMed]

2. Banales, J.M.; Cardinale, V.; Carpino, G.; Marzioni, M.; Andersen, J.B.; Invernizzi, P.; Lind, G.E.; Folseraas, T.; Forbes, S.J.; Fouassier, L.; et al. Expert consensus document: Cholangiocarcinoma: Current knowledge and future perspectives consensus statement from the European Network for the Study of Cholangiocarcinoma (ENS-CCA). Nat. Rev. Gastroenterol. Hepatol. 2016, 13, 261-280. [CrossRef] [PubMed]

3. Nakeeb, A.; Pitt, H.A.; Sohn, T.A.; Coleman, J.; Abrams, R.A.; Piantadosi, S.; Hruban, R.H.; Lillemoe, K.D.; Yeo, C.J.; Cameron, J.L. Cholangiocarcinoma. A spectrum of intrahepatic, perihilar, and distal tumors. Ann. Surg. 1996, 224, 463-475. [CrossRef]

4. DeOliveira, M.L.; Cunningham, S.C.; Cameron, J.L.; Kamangar, F.; Winter, J.M.; Lillemoe, K.D.; Choti, M.A.; Yeo, C.J.; Schulick, R.D. Cholangiocarcinoma: Thirty-one-year experience with 564 patients at a single institution. Ann. Surg. 2007, 245, 755-762. [CrossRef] [PubMed]

5. Valle, J.; Wasan, H.; Palmer, D.H.; Cunningham, D.; Anthoney, A.; Maraveyas, A.; Madhusudan, S.; Iveson, T.; Hughes, S.; Pereira, S.P.; et al. Cisplatin plus gemcitabine versus gemcitabine for biliary tract cancer. N. Engl. J. Med. 2010, 362, 1273-1281. [CrossRef] [PubMed]

6. Suda, T.; Liu, D. Hydrodynamic gene delivery: Its principles and applications. Mol. Ther. J. Am. Soc. Gene Ther. 2007, 15, 2063-2069. [CrossRef]

7. Mikkelsen, J.G.; Yant, S.R.; Meuse, L.; Huang, Z.; Xu, H.; Kay, M.A. Helper-Independent Sleeping Beauty transposon-transposase vectors for efficient nonviral gene delivery and persistent gene expression in vivo. Mol. Ther. J. Am. Soc. Gene Ther. 2003, 8, 654-665. [CrossRef]

8. Yant, S.R.; Meuse, L.; Chiu, W.; Ivics, Z.; Izsvak, Z.; Kay, M.A. Somatic integration and long-term transgene expression in normal and haemophilic mice using a DNA transposon system. Nat. Genet. 2000, 25, 35-41. [CrossRef]

9. Chen, X.; Calvisi, D.F. Hydrodynamic Transfection for Generation of Novel Mouse Models for Liver Cancer Research. Am. J. Pathol. 2014, 184, 912-923. [CrossRef]

10. Carlson, C.M.; Frandsen, J.L.; Kirchhof, N.; McIvor, R.S.; Largaespada, D.A. Somatic integration of an oncogene-harboring Sleeping Beauty transposon models liver tumor development in the mouse. Proc. Natl. Acad. Sci. USA 2005, 102, 17059-17064. [CrossRef]

11. Li, X.L.; Tao, J.Y.; Cigliano, A.; Sini, M.; Calderaro, J.; Azoulay, D.; Wang, C.M.; Liu, Y.; Jiang, L.J.; Evert, K.; et al. Co-activation of PIK3CA and Yap promotes development of hepatocellular and cholangiocellular tumors in mouse and human liver. Oncotarget 2015, 6, 10102-10115. [CrossRef] [PubMed]

12. Fan, B.; Malato, Y.; Calvisi, D.F.; Naqvi, S.; Razumilava, N.; Ribback, S.; Gores, G.J.; Dombrowski, F.; Evert, M.; Chen, X.; et al. Cholangiocarcinomas can originate from hepatocytes in mice. J. Clin. Investig. 2012, 122, 2911-2915. [CrossRef] [PubMed]

13. Zhang, S.S.; Song, X.H.; Cao, D.; Xu, Z.; Fan, B.A.; Che, L.; Hu, J.J.; Chen, B.; Dong, M.J.; Pilo, M.G.; et al. Pan-mTOR inhibitor MLN0128 is effective against intrahepatic cholangiocarcinoma in mice. J. Hepatol. 2017, 67, 1194-1203. [CrossRef] [PubMed]

14. Zhang, S.S.; Wang, J.X.; Wang, H.C.; Fan, L.L.; Fan, B.; Zeng, B.; Tao, J.Y.; Li, X.L.; Che, L.; Cigliano, A.; et al. Hippo Cascade Controls Lineage Commitment of Liver Tumors in Mice and Humans. Am. J. Pathol. 2018, 188, 995-1006. [CrossRef]

15. Li, L.; Che, L.; Tharp, K.M.; Park, H.M.; Pilo, M.G.; Cao, D.; Cigliano, A.; Latte, G.; Xu, Z.; Ribback, S.; et al. Differential Requirement for De Novo Lipogenesis in Cholangiocarcinoma and Hepatocellular Carcinoma of Mice and Humans. Hepatology 2016, 63, 1900-1913. [CrossRef]

16. Ho, C.; Wang, C.M.; Mattu, S.; Destefanis, G.; Ladu, S.; Delogu, S.; Armbruster, J.; Fan, L.L.; Lee, S.A.; Jiang, L.J.; et al. AKT (v-akt murine thymoma viral oncogene homolog 1) and N-Ras (neuroblastoma ras viral oncogene homolog) coactivation in the mouse liver promotes rapid carcinogenesis by way of mTOR (mammalian target of rapamycin complex 1), FOXM1 (forkhead box M1)/SKP2, and c-Myc pathways. Hepatology 2012, 55, 833-845.

17. Dong, M.J.; Liu, X.Q.; Evert, K.; Utpatel, K.; Peters, M.; Zhang, S.S.; Xu, Z.; Che, L.; Cigliano, A.; Ribback, S.; et al. Efficacy of MEK inhibition in a K-Ras-driven cholangiocarcinoma preclinical model. Cell Death Dis. 2018, 9, 31. [CrossRef] 
18. Che, L.; Fan, B.; Pilo, M.G.; Xu, Z.; Liu, Y.; Cigliano, A.; Cossu, A.; Palmieri, G.; Pascale, R.M.; Porcu, A.; et al. Jagged 1 is a major Notch ligand along cholangiocarcinoma development in mice and humans. Oncogenesis 2016, 5, e274. [CrossRef]

19. Tschaharganeh, D.F.; Xue, W.; Calvisi, D.F.; Evert, M.; Michurina, T.V.; Dow, L.E.; Banito, A.; Katz, S.F.; Kastenhuber, E.R.; Weissmueller, S.; et al. p53-Dependent Nestin Regulation Links Tumor Suppression to Cellular Plasticity in Liver Cancer. Cell 2014, 158, 579-592. [CrossRef]

20. Seehawer, M.; Heinzmann, F.; D'Artista, L.; Harbig, J.; Roux, P.F.; Hoenicke, L.; Dang, H.; Klotz, S.; Robinson, L.; Dore, G.; et al. Necroptosis microenvironment directs lineage commitment in liver cancer. Nature 2018, 562, 69-75. [CrossRef]

21. Weber, J.; Ollinger, R.; Friedrich, M.; Ehmer, U.; Barenboim, M.; Steiger, K.; Heid, I.; Mueller, S.; Maresch, R.; Engleitner, T.; et al. CRISPR/Cas9 somatic multiplex-mutagenesis for high-throughput functional cancer genomics in mice. Proc. Natl. Acad. Sci. USA 2015, 112, 13982-13987. [CrossRef]

22. Xue, W.; Chen, S.; Yin, H.; Tammela, T.; Papagiannakopoulos, T.; Joshi, N.S.; Cai, W.; Yang, G.; Bronson, R.; Crowley, D.G.; et al. CRISPR-mediated direct mutation of cancer genes in the mouse liver. Nature 2014, 514, 380-384. [CrossRef]

23. Yamada, D.; Rizvi, S.; Razumilava, N.; Bronk, S.F.; Davila, J.I.; Champion, M.D.; Borad, M.J.; Bezerra, J.A.; Chen, X.; Gores, G.J. IL-33 Facilitates Oncogene-Induced Cholangiocarcinoma in Mice by an Interleukin-6-Sensitive Mechanism. Hepatology 2015, 61, 1627-1642. [CrossRef]

24. Gurlevik, E.; Fleischmann-Mundt, B.; Armbrecht, N.; Longerich, T.; Woller, N.; Kloos, A.; Hoffmann, D.; Schambach, A.; Wirth, T.C.; Manns, M.P.; et al. Adjuvant gemcitabine therapy improves survival in a locally induced, R0-resectable model of metastatic intrahepatic cholangiocarcinoma. Hepatology (Baltimore, Md) 2013, 58, 1031-1041. [CrossRef]

25. Sugihara, T.; Isomoto, H.; Gores, G.; Smoot, R. YAP and the Hippo pathway in cholangiocarcinoma. J. Gastroenterol. 2019, 54, 485-491. [CrossRef]

26. Tschaharganeh, D.F.; Chen, X.; Latzko, P.; Malz, M.; Gaida, M.M.; Felix, K.; Ladu, S.; Singer, S.; Pinna, F.; Gretz, N.; et al. Yes-Associated Protein Up-regulates Jagged-1 and Activates the NOTCH Pathway in Human Hepatocellular Carcinoma. Gastroenterology 2013, 144, 1530-1542. [CrossRef]

27. Doudna, J.A.; Charpentier, E. Genome editing. The new frontier of genome engineering with CRISPR-Cas9. Science (New York, NY) 2014, 346, 1258096. [CrossRef]

28. Frese, K.K.; Tuveson, D.A. Maximizing mouse cancer models. Nat. Rev. Cancer 2007, 7, 645-658. [CrossRef]

29. Walrath, J.C.; Hawes, J.J.; Van Dyke, T.; Reilly, K.M. Genetically engineered mouse models in cancer research. Adv. Cancer Res. 2010, 106, 113-164.

30. Ellwood-Yen, K.; Graeber, T.G.; Wongvipat, J.; Iruela-Arispe, M.L.; Zhang, J.; Matusik, R.; Thomas, G.V.; Sawyers, C.L. Myc-driven murine prostate cancer shares molecular features with human prostate tumors. Cancer Cell 2003, 4, 223-238. [CrossRef]

31. Lee, J.-S.; Chu, I.-S.; Mikaelyan, A.; Calvisi, D.F.; Heo, J.; Reddy, J.K.; Thorgeirsson, S.S. Application of comparative functional genomics to identify best-fit mouse models to study human cancer. Nat. Genet. 2004, 36, 1306-1311. [CrossRef]

32. Sweet-Cordero, A.; Mukherjee, S.; Subramanian, A.; You, H.; Roix, J.J.; Ladd-Acosta, C.; Mesirov, J.; Golub, T.R.; Jacks, T. An oncogenic KRAS2 expression signature identified by cross-species gene-expression analysis. Nat. Genet. 2005, 37, 48-55. [CrossRef]

33. Kersten, K.; de Visser, K.E.; van Miltenburg, M.H.; Jonkers, J. Genetically engineered mouse models in oncology research and cancer medicine. EMBO Mol. Med. 2017, 9, 137-153. [CrossRef]

34. Zou, S.; Li, J.; Zhou, H.; Frech, C.; Jiang, X.; Chu, J.S.C.; Zhao, X.; Li, Y.; Li, Q.; Wang, H.; et al. Mutational landscape of intrahepatic cholangiocarcinoma. Nat. Commun. 2014, 5, 5696. [CrossRef]

35. Farshidfar, F.; Zheng, S.; Gingras, M.-C.; Newton, Y.; Shih, J.; Robertson, A.G.; Hinoue, T.; Hoadley, K.A.; Gibb, E.A.; Roszik, J.; et al. Integrative Genomic Analysis of Cholangiocarcinoma Identifies Distinct IDH-Mutant Molecular Profiles. Cell Rep. 2017, 18, 2780-2794. [CrossRef]

36. Jusakul, A.; Cutcutache, I.; Yong, C.H.; Lim, J.Q.; Huang, M.N.; Padmanabhan, N.; Nellore, V.; Kongpetch, S.; Ng, A.W.T.; Ng, L.M.; et al. Whole-Genome and Epigenomic Landscapes of Etiologically Distinct Subtypes of Cholangiocarcinoma. Cancer Discov. 2017, 7, 1116-1135. [CrossRef] 
37. Andersen, J.B.; Spee, B.; Blechacz, B.R.; Avital, I.; Komuta, M.; Barbour, A.; Conner, E.A.; Gillen, M.C.; Roskams, T.; Roberts, L.R.; et al. Genomic and genetic characterization of cholangiocarcinoma identifies therapeutic targets for tyrosine kinase inhibitors. Gastroenterology 2012, 142, 1021-1031. [CrossRef]

38. Robertson, S.; Hyder, O.; Dodson, R.; Nayar, S.K.; Poling, J.; Beierl, K.; Eshleman, J.R.; Lin, M.-T.; Pawlik, T.M.; Anders, R.A. The frequency of KRAS and BRAF mutations in intrahepatic cholangiocarcinomas and their correlation with clinical outcome. Hum. Pathol. 2013, 44, 2768-2773. [CrossRef]

39. Nepal, C.; O’Rourke, C.J.; Oliveira, D.V.; Taranta, A.; Shema, S.; Gautam, P.; Calderaro, J.; Barbour, A.; Raggi, C.; Wennerberg, K.; et al. Genomic Perturbations Reveal Distinct Regulatory Networks in Intrahepatic Cholangiocarcinoma. Hepatology (Baltimore, Md) 2017, 68, 949-963. [CrossRef]

40. Xu, X.; Kobayashi, S.; Qiao, W.; Li, C.; Xiao, C.; Radaeva, S.; Stiles, B.; Wang, R.-H.; Ohara, N.; Yoshino, T.; et al. Induction of intrahepatic cholangiocellular carcinoma by liver-specific disruption of Smad4 and Pten in mice. J. Clin. Investig. 2006, 116, 1843-1852. [CrossRef]

41. Marsh, V.; Davies, E.J.; Williams, G.T.; Clarke, A.R. PTEN loss and KRAS activation cooperate in murine biliary tract malignancies. J. Pathol. 2013, 230, 165-173. [CrossRef]

42. Ikenoue, T.; Terakado, Y.; Nakagawa, H.; Hikiba, Y.; Fujii, T.; Matsubara, D.; Noguchi, R.; Zhu, C.; Yamamoto, K.; Kudo, Y.; et al. A novel mouse model of intrahepatic cholangiocarcinoma induced by liver-specific Kras activation and Pten deletion. Sci. Rep. 2016, 6, 23899. [CrossRef]

43. Lin, Y.K.; Fang, Z.; Jiang, T.Y.; Wan, Z.H.; Pan, Y.F.; Ma, Y.H.; Shi, Y.Y.; Tan, Y.X.; Dong, L.W.; Zhang, Y.J.; et al. Combination of Kras activation and PTEN deletion contributes to murine hepatopancreatic ductal malignancy. Cancer Lett. 2018, 421, 161-169. [CrossRef]

44. Katz, S.F.; Lechel, A.; Obenauf, A.C.; Begus-Nahrmann, Y.; Kraus, J.M.; Hoffmann, E.M.; Duda, J.; Eshraghi, P.; Hartmann, D.; Liss, B.; et al. Disruption of Trp53 in Livers of Mice Induces Formation of Carcinomas with Bilineal Differentiation. Gastroenterology 2012, 142, 1229-1239. [CrossRef]

45. O'Dell, M.R.; Huang, J.L.; Whitney-Miller, C.L.; Deshpande, V.; Rothberg, P.; Grose, V.; Rossi, R.M.; Zhu, A.X.; Land, H.; Bardeesy, N.; et al. Kras(G12D) and p53 mutation cause primary intrahepatic cholangiocarcinoma. Cancer Res. 2012, 72, 1557-1567. [CrossRef]

46. Hill, M.A.; Alexander, W.B.; Guo, B.; Kato, Y.; Patra, K.; O’Dell, M.R.; McCall, M.N.; Whitney-Miller, C.L.; Bardeesy, N.; Hezel, A.F. Kras and Tp53 Mutations Cause Cholangiocyte- and Hepatocyte-Derived Cholangiocarcinoma. Cancer Res. 2018, 78, 4445-4451. [CrossRef]

47. Ikenoue, T.; Terakado, Y.; Zhu, C.; Liu, X.; Ohsugi, T.; Matsubara, D.; Fujii, T.; Kakuta, S.; Kubo, S.; Shibata, T.; et al. Establishment and analysis of a novel mouse line carrying a conditional knockin allele of a cancer-specific FBXW7 mutation. Sci. Rep. 2018, 8, 2021. [CrossRef]

48. Saha, S.K.; Parachoniak, C.A.; Ghanta, K.S.; Fitamant, J.; Ross, K.N.; Najem, M.S.; Gurumurthy, S.; Akbay, E.A.; Sia, D.; Cornella, H.; et al. Mutant IDH inhibits HNF-4 alpha to block hepatocyte differentiation and promote biliary cancer. Nature 2014, 513, 110-114. [CrossRef]

49. Zender, S.; Nickeleit, I.; Wuestefeld, T.; Sorensen, I.; Dauch, D.; Bozko, P.; El-Khatib, M.; Geffers, R.; Bektas, H.; Manns, M.P.; et al. A Critical Role for Notch Signaling in the Formation of Cholangiocellular Carcinomas. Cancer Cell 2013, 23, 784-795. [CrossRef]

50. El Khatib, M.; Bozko, P.; Palagani, V.; Malek, N.P.; Wilkens, L.; Plentz, R.R. Activation of Notch Signaling Is Required for Cholangiocarcinoma Progression and Is Enhanced by Inactivation of p53 In Vivo. PLoS ONE 2013, 8, e77433. [CrossRef]

51. Yuan, D.T.; Huang, S.; Berger, E.; Liu, L.; Gross, N.; Heinzmann, F.; Ringelhan, M.; Connor, T.O.; Stadler, M.; Meister, M.; et al. Kupffer Cell-Derived Tnf Triggers Cholangiocellular Tumorigenesis through JNK due to Chronic Mitochondrial Dysfunction and ROS. Cancer Cell 2017, 31, 771-789. [CrossRef]

52. Nakagawa, H.; Suzuki, N.; Hirata, Y.; Hikiba, Y.; Hayakawa, Y.; Kinoshita, H.; Ihara, S.; Uchino, K.; Nishikawa, Y.; Ijichi, H.; et al. Biliary epithelial injury-induced regenerative response by IL-33 promotes cholangiocarcinogenesis from peribiliary glands. Proc. Natl. Acad. Sci. USA 2017, 114, E3806-E3815. [CrossRef]

53. Saborowski, A.; Saborowski, M.; Davare, M.A.; Druker, B.J.; Klimstra, D.S.; Lowe, S.W. Mouse model of intrahepatic cholangiocarcinoma validates FIG-ROS as a potent fusion oncogene and therapeutic target. Proc. Natl. Acad. Sci. USA 2013, 110, 19513-19518. [CrossRef] [PubMed] 
54. Saborowski, A.; Wolff, K.; Spielberg, S.; Beer, B.; Hartleben, B.; Erlangga, Z.; Becker, D.; Dow, L.E.; Marhenke, S.; Woller, N.; et al. Murine Liver Organoids as a Genetically Flexible System to Study Liver Cancer In Vivo and In Vitro. Hepatol. Commun. 2019, 3, 423-436. [CrossRef]

55. Sekiya, S.; Suzuki, A. Intrahepatic cholangiocarcinoma can arise from Notch-mediated conversion of hepatocytes. J. Clin. Investig. 2012, 122, 3914-3918. [CrossRef]

56. Guest, R.V.; Boulter, L.; Dwyer, B.J.; Kendall, T.J.; Man, T.Y.; Minnis-Lyons, S.E.; Lu, W.Y.; Robson, A.J.; Gonzalez, S.F.; Raven, A.; et al. Notch3 drives development and progression of cholangiocarcinoma. Proc. Natl. Acad. Sci. USA 2016, 113, 12250-12255. [CrossRef]

57. Farazi, P.A.; Zeisberg, M.; Glickman, J.; Zhang, Y.; Kalluri, R.; DePinho, R.A. Chronic bile duct injury associated with fibrotic matrix microenvironment provokes cholangiocarcinoma in p53-deficient mice. Cancer Res. 2006, 66, 6622-6627. [CrossRef]

58. Postic, C.; Magnuson, M.A. DNA excision in liver by an albumin-Cre transgene occurs progressively with age. Genesis 2000, 26, 149-150. [CrossRef]

59. Mu, X.; Pradere, J.-P.; Affò, S.; Dapito, D.H.; Friedman, R.; Lefkovitch, J.H.; Schwabe, R.F. Epithelial Transforming Growth Factor- $\beta$ Signaling Does Not Contribute to Liver Fibrosis but Protects Mice from Cholangiocarcinoma. Gastroenterology 2016, 150, 720-733. [CrossRef]

60. Holczbauer, A.; Factor, V.M.; Andersen, J.B.; Marquardt, J.U.; Kleiner, D.E.; Raggi, C.; Kitade, M.; Seo, D.; Akita, H.; Durkin, M.E.; et al. Modeling pathogenesis of primary liver cancer in lineage-specific mouse cell types. Gastroenterology 2013, 145, 221-231. [CrossRef]

61. Borger, D.R.; Tanabe, K.K.; Fan, K.C.; Lopez, H.U.; Fantin, V.R.; Straley, K.S.; Schenkein, D.P.; Hezel, A.F.; Ancukiewicz, M.; Liebman, H.M.; et al. Frequent mutation of isocitrate dehydrogenase (IDH) 1 and IDH2 in cholangiocarcinoma identified through broad-based tumor genotyping. Oncologist 2012, 17, 72-79. [CrossRef] [PubMed]

62. Wang, P.; Dong, Q.; Zhang, C.; Kuan, P.F.; Liu, Y.; Jeck, W.R.; Andersen, J.B.; Jiang, W.; Savich, G.L.; Tan, T.X.; et al. Mutations in isocitrate dehydrogenase 1 and 2 occur frequently in intrahepatic cholangiocarcinomas and share hypermethylation targets with glioblastomas. Oncogene 2013, 32, 3091-3100. [CrossRef] [PubMed]

63. Dang, L.; White, D.W.; Gross, S.; Bennett, B.D.; Bittinger, M.A.; Driggers, E.M.; Fantin, V.R.; Jang, H.G.; Jin, S.; Keenan, M.C.; et al. Cancer-associated IDH1 mutations produce 2-hydroxyglutarate. Nature 2010, 465, 966. [CrossRef] [PubMed]

64. Rios, A.C.; Fu, N.Y.; Cursons, J.; Lindeman, G.J.; Visvader, J.E. The complexities and caveats of lineage tracing in the mammary gland. Breast Cancer Res. BCR 2016, 18, 116. [CrossRef]

65. Sia, D.; Villanueva, A.; Friedman, S.L.; Llovet, J.M. Liver Cancer Cell of Origin, Molecular Class, and Effects onPatient Prognosis. Gastroenterology 2017, 152, 745-761. [CrossRef]

66. Dill, M.T.; Tornillo, L.; Fritzius, T.; Terracciano, L.; Semela, D.; Bettler, B.; Heim, M.H.; Tchorz, J.S. Constitutive Notch2 signaling induces hepatic tumors in mice. Hepatology 2013, 57, 1607-1619. [CrossRef]

67. Villanueva, A.; Alsinet, C.; Yanger, K.; Hoshida, Y.; Zong, Y.; Toffanin, S.; Rodriguez-Carunchio, L.; Sole, M.; Thung, S.; Stanger, B.Z.; et al. Notch signaling is activated in human hepatocellular carcinoma and induces tumor formation in mice. Gastroenterology 2012, 143, 1660-1669. [CrossRef]

68. Shin, S.; Wangensteen, K.J.; Teta-Bissett, M.; Wang, Y.J.; Mosleh-Shirazi, E.; Buza, E.L.; Greenbaum, L.E.; Kaestner, K.H. Genetic lineage tracing analysis of the cell of origin of hepatotoxin-induced liver tumors in mice. Hepatology (Baltimore, Md) 2016, 64, 1163-1177. [CrossRef]

69. Guest, R.V.; Boulter, L.; Kendall, T.J.; Minnis-Lyons, S.E.; Walker, R.; Wigmore, S.J.; Sansom, O.J.; Forbes, S.J. Cell lineage tracing reveals a biliary origin of intrahepatic cholangiocarcinoma. Cancer Res. 2014, 74, 1005-1010. [CrossRef]

70. Cadamuro, M.; Brivio, S.; Stecca, T.; Kaffe, E.; Mariotti, V.; Milani, C.; Fiorotto, R.; Spirli, C.; Strazzabosco, M.; Fabris, L. Animal models of cholangiocarcinoma: What they teach us about the human disease. Clin. Res. Hepatol Gas. 2018, 42, 403-415. [CrossRef]

71. Loeuillard, E.; Fischbach, S.R.; Gores, G.J.; Rizvi, S. Animal models of cholangiocarcinoma. Biochim. Biophys. Acta Mol. Basis Dis. 2018, 1865, 982-992. [CrossRef] [PubMed]

(C) 2019 by the authors. Licensee MDPI, Basel, Switzerland. This article is an open access article distributed under the terms and conditions of the Creative Commons Attribution (CC BY) license (http://creativecommons.org/licenses/by/4.0/). 